\title{
EDUKASI PERILAKU CUCI TANGAN PAKAI SABUN PADA SISWA SD DI TANGERANG SELATAN
}

\section{EDUCATION OF WASHING HANDS WITH SOAP TO ELEMENTARY SCHOOL STUDENTS IN TANGERANG SELATAN}

\author{
${ }^{1)}$ Narila Mutia Nasir ${ }^{*}{ }^{2)}$ Wirda Farah, ${ }^{3)}$ Ragma Desilfa, ${ }^{4)}$ Didi Khaerudin, ${ }^{5}$ Yunita Safira, ${ }^{6}$ Virlian \\ Aulia Intan, ${ }^{7)}$ Auliya Saphira Maulana, ${ }^{8}$ Mawaddah Warahmah \\ 1,2,3,4,5,6,7,8) Program Studi Kesehatan Masyarakat, Fakultas Ilmu Kesehatan \\ Universitas Islam Negeri Syarif Hidayatullah Jakarta \\ Jl. Kertamukti No.5, Pisangan, Ciputat, Tangerang Selatan \\ Email: narilamutia@uinjkt.ac.id
}

\begin{abstract}
ABSTRAK
Perilaku mencuci tangan belum menjadi budaya dalam masyarakat, Salah satu penyebab kondisi ini adalah kurangnya pengetahuan tentang hal tersebut, terutama pada anak sekolah. Kegiatan pengabdian masyarakat yang dilakukan oleh Tim Kesehatan Masyarakat UIN Syarif Hidayatullah bertujuan untuk meningatkan pengetahuan tentang CTPS sebagai salah satu upaya untuk mencegah kejadian diare. Kegiatan ini dilaksanakan kepada siswa di SDN 02 Rempoa, Tangerang Selatan dalam bentuk edukasi dan praktik cuci tangan. Hasil pre dan post-test menunjukkan adanya kenaikan rata-rata pengetahuan dari 59 menjadi 78.25 poin. Peningkatan pengetahuan ini dapat berdampak pada peningkatan praktik CTPS yang lebih baik. Selain itu para siswa diharapkan dapat menjadi agen perubahan pada lingkungannya serta menjadikan CTPS sebagai budaya yang merupakan bagian dari kehidupan seharihari. Dengan denikian secara tidak langsung juga akan menurunkan risiko penyakit menular terutama diare.
\end{abstract}

Kata Kunci: Cuci tangan, diare, pengetahuan, edukasi, anak sekolah

\section{ABSTRACT}

Hand washing behavior has not yet a culture in the society. This condition is caused by the lack of knowledge about the issue, especially among school children. Community service activity undertaken by the Public Health team of UIN Syarif Hidayatullah aimed to increase the knowledge about WHWS as an effort to prevent the occurrence of diarrhea. This activity was carried out for elementary students at SDN 02 Rempoa, South Tangerang by performing educational session and practice of hand washing. The result of pre and post-test showed an improvement of average knowledge, from 59 to 78.25 points. The increasing of knowledge might have an impact to better WHWS practices. In addition, the students are expected to be the agents of change in their environment and make WHWS a culture in the daily life. Thus, it also will indirectly reduce the risk of infectious diseases, especially diarrhea.

Keyword: washing hands, diarrhea, knowledge, education, student 


\section{PENDAHULUAN}

Cuci Tangan Pakai Sabun (CTPS) adalah suatu perilaku yang dapat mendukung hidup bersih dan sehat serta terhindar dari penyakit menular, salah satunya diare. Risiko anak menderita diare akan menurun 40\% jika ia selalu melakukan CTPS (UNICEF, 2020). Kasus diare banyak menyerang anak-anak termasuk anak sekolah. Penelitian yang dilakukan oleh Utomo, dkk serta Rompas, dkk pada anak sekolah dasar (SD) di tempat yang berbeda menemukan hubungan yang bermakna antara perilaku CTPS dan kejadian diare (Rompas, Tuda dan Ponidjan, 2013; Utomo, Alfiyanti dan Nurahman, 2013). Hasil penelitian lainnya di Jember dan Manado pada anak sekolah juga menemukan pola hubungan yang sama (Purwandari, Ardiana dan Wantiyah, 2013; Djarkoni et al., 2014).

Studi pendahuluan yang dilakukan di wilayah Rempoa, Tangerang Selatan menemukan 360 kasus diare yang sebagian besar terjadi pada balita dan anak usia sekolah. Diare disebabkan oleh agen penyebab penyakit yaitu bakteri. Salah satu cara yang efektif untuk menghambat transmisi bakteri adalah melalui CTPS karena dengan mencuci tangan maka risiko terkena diare ikut menurun (Curtis dan Cairncross, 2003). Akan tetapi, CTPS belum menjadi budaya atau kebiasaan pada anak-anak. Oleh karena itu, tim pengabdian masyarakat merasa perlu untuk melakukan edukasi dan praktik CTPS pada anak SD di wilayah Rempoa yang memiliki banyak kasus diare.

Kegiatan pengabdian masyarakat ini bertujuan untuk meningkatkan pengetahuan anak SD terkait pencegahan diare melalui perilaku CTPS. Diharapkan para siswa akan makin terbiasa melakukan CTPS sehingga secara tidak langsung nantinya dapat menurunkan kesakitan akibat diare. Edukasi dan praktik tentang CTPS ini bukan hanya dapat memberi manfaat bagi individu siswa sendiri tetapi juga bagi lingkungan sekitarnya, terutama jika para siswa dapat berperan sebagai agen perubahan bagi teman sebayanya.

\section{METODE}

Pada tahapan persiapan, tim pengabdian masyarakat menentukan sekolah yang akan dijadikan sasaran kegiatan berdasarkan data studi pendahuluan. Tim memutuskan SDN 02 Rempoa untuk menjadi tempat pelaksanaan kegiatan edukasi dan melakukan koordinasi dengan pihak sekolah. Setelah mendapatkan masukan dari pihak sekolah, maka ditentukan kelas yang akan menerima kegiatan tersebut dan tanggal pelaksanaan agar tidak mengganggu kegiatan pengajaran.

Pelaksanaan kegiatan pengabdian masyarakat ini dilakukan dengan metode penyuluhan pada anak SDN Rempoa di Tangerang Selatan pada Senin, 3 Februari 2020. Target pelaksanaan edukasi ini diberikan kepada satu kelas 3 yang beranggotakan 32 siswa. Kegiatan diawali dengan pengisian pre-test oleh para siswa. Selanjutnya penyampaian materi edukasi tentang Cuci Tangan Pakai Sabun dan tanya jawab. Untuk lebih membantu pemahaman para siswa, maka tim memutar video dengan menggunakan proyektor tentang cara Cuci Tangan Pakai Sabun.

Setelah para siswa SD tersebut melihat dan memahani pesan CTPS pada video, mereka dibagi atas beberapa kelompok. Setiap kelompok bergantian ke depan memperagakan langkah cuci tangan sambal diiringi lagu CTPS. Untuk mengetahui apakah para siswa tersebut memahami pesan edukasi tentang cuci tangan maka dilakukan post-test. Selain pemutaran video, tim juga membuat poster terkait 6 langkah CTPS yang baik dan benar yang bisa ditempelkan di dekat tempat cuci tangan.

\section{HASIL DAN PEMBAHASAN}

Kegiatan pengabdian masyarakat ini bertujuan untuk meningkatkan pengetahuan anak sekolah tentang perilaku cuci tangan yang benar. Perilaku cuci tangan pakai sabun jika 
dilakukan secara benar akan dapat membantu menurunkan risiko penyakit menular salah satunya penyakit diare. Berdasarkan data yang diperoleh dari survei cepat yang dilakukan tim pengabdian masyarakat ini, kasus diare yang terjadi di wilayah Rempoa Tangerang Selatan banyak terjadi pada usia balita dan anak sekolah. Oleh karena itu kegiatan edukasi kepada anak sekolah terutama anak SD dapat mendorong anak-anak untuk berperilaku hidup bersih dan sehat, salah satunya dengan melakukan praktik cuci tangan pakai sabun sesuai petunjuk yang benar. Gambar 1 menunjukkan situasi saat pelaksanaan edukasi.
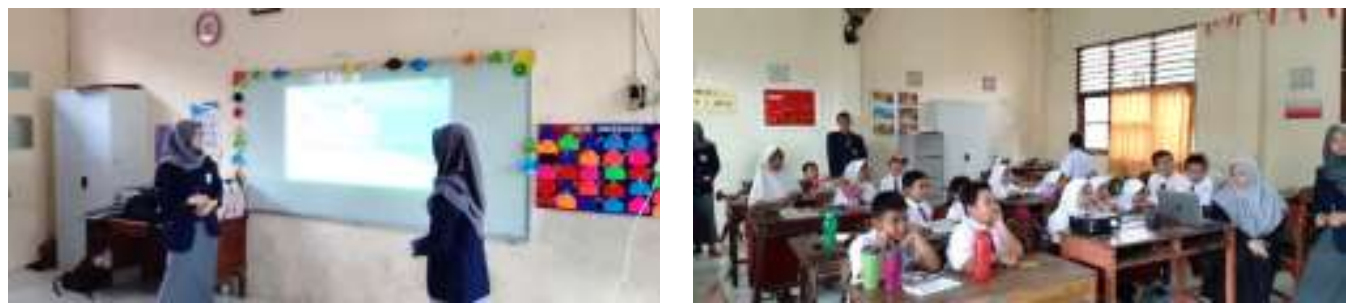

Sumber: Dokumentasi pribadi

Gambar 1. Pelaksanaan Edukasi

Sebanyak 25 siswa mengikuti kegiatan ini dari target 32 siswa yang direncanakan, sehingga tingkat kehadirannya adalah $78.12 \%$. Berdasarkan hasil pre-test dan post-test terjadi kenaikan rata-rata nilai pengetahuan siswa SD yang menerima edukasi dan praktik terkait CTPS yaitu dari 59 menjadi 78,25 poin. Oleh karena itu tercatat adanya peningkatan pengetahuan siswa sebesar $32.6 \%$ seperti yang ditunjukkan oleh gambar 2. Diantara siswa yang menerima edukasi dan praktik CTPS, 84\% dari mereka (21 dari 25 siswa) mengalami kenaikan skor pengetahuan sebelum dan sesudah edukasi.

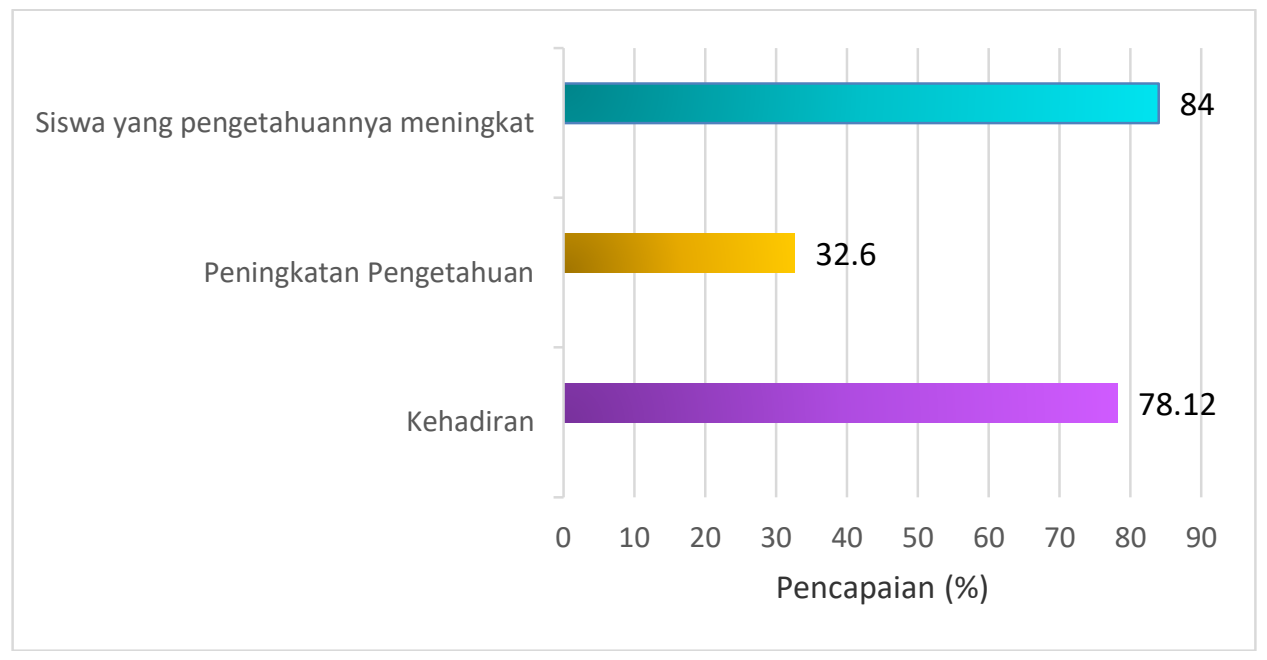

Gambar 2. Hasil pencapaian kegiatan Edukasi dan praktik CTPS di SDN 02 Rempoa

Tingkat pengetahuan menjadi salah satu faktor penting untuk mendukung perilaku CTPS yang benar. Penelitian yang dilakukan Kartika, dkk pada anak sekolah di Kota Semarang menunjukkan bahwa ada hubungan yang signifikan antara pengetahuan tentang CTPS dan perilaku CTPS. Mereka yang memiliki pengetahuan baik lebih banyak yang melakukan CTPS secara benar (Kartika, Widagdo dan Sugihantono, 2016).

Pelaksaanaan edukasi dan praktik CTPS pada kegiatan pengabdian masyarakat ini selain menggunakan metode penyuluhan juga dilakukan pemutaran video langkah CTPS. Hal ini untuk memperkuat pengetahuan yang dimiliki siswa. Penelitian yang dilakukan oleh Ashari, dkk menunjukkan siswa yang diberikan materi senam CTPS memiliki pengetahuan 
lebih baik daripada mereka yang tidak menerima informasi tentang CTPS (Ashari, Ganing dan Mappau, 2020). Hasil yang diperoleh dalam kegiatan pengabdian masyarakat ini tidak jauh berbeda dengan kegiatan yang dilakukan oleh Tulak, dkk ketika mengedukasi anak madrasah tentang CTPS.

Walaupun kegiatan edukasi dan praktik tentang CTPS lebih bersifat demostrasi, tetapi diharapkan dapat menjadi suatu pemicu untuk meningkatkan kesadaran para siswa tentang pentingnya CTPS serta menjadikannya kebiasaan sehari-hari. Intervensi yang dilakukan oleh Zhang, dkk di Uganda juga menunjukkan bahwa promosi tentang CTPS adalah hal penting dan berpotensi menurunkan risiko penyakit diare pada anak-anak (Zhang et al., 2013) Apabila siswa yang mengikuti kegiatan pengabdian masyarakat ini sudah terbiasa dengan CTPS, diharapkan mereka akan menjadi agen perubahan dalam lingkungannya.

\section{KESIMPULAN DAN SARAN}

Cuci Tangan Pakai Sabun (CTPS) merupakan bagian dari perilaku hidup bersih dan sehat yang harus ditanamkan sejak dini dan menjadi kebiasaan atau budaya sehari-hari. Hal ini mengingat bahwa kebiasaan tersebut akan membawa dampak positif kepada status kesehatan anak-anak secara holistik, termasuk pencegahan terhadap kejadian diare. Kegiatan pengabdian masyarakat ini diharapkan menjadi pendorong agar anak-anak sekolah dapat melakukan langkah CTPS secara benar dan menjadikannya sebagai suatu budaya dalam kehidupannya.

\section{UCAPAN TERIMA KASIH}

Tim penulis mengucapkan penghargaan dan terima kasih kepada pihak SDN 02 Rempoa dan siswa yang telah berpartisipasi aktif dalam kegiatan pengabdian masyarakat ini sehingga dapat berjalan lancer dan memberi manfaat. Rasa terima kasih juga diberikan kepada pihak Puskesmas Ciputat Timur atas kerjasamanya.

\section{DAFTAR PUSTAKA}

Ashari, A. E., Ganing, A. dan Mappau, Z. 2020. Peningkatan Pengetahuan, Sikap Dan Praktik Cuci Tangan Pakai Sabun Pada Anak Kelas V Sekolah Dasarmelalui Senam Cuci Tangan Pakai Sabun. Jurnal Ilmiah Permas: Jurnal Ilmiah STIKES Kendal, 10(1), pp. 11-18. Available at: http://journal.stikeskendal.ac.id/index.php/PSKM/article/view/635/389.

Curtis, V. and Cairncross, S. 2003. Effect of washing hands with soap on diarrhoea risk in the community: A systematic review. Lancet Infectious Diseases, 3(5), pp. 275-281. doi: 10.1016/S1473-3099(03)00606-6.

Djarkoni, I. . et al. 2014. Hubungan Perilaku Cuci Tangan Pakai Sabun Dengan Kejadian Diare Di Sd Advent Sario Kota Manado', Jurnal Kedokteran Komunitas Dan Tropik, 2(3), pp. 95-98.

Kartika, M., Widagdo, L. and Sugihantono, A. 2016. Faktor-Faktor Yang Berhubungan Dengan Perilaku Cuci Tangan Pakai Sabun Pada Siswa Sekolah Dasar Negeri Sambiroto 01 Kota Semarang', Jurnal Kesehatan Masyarakat (e-Journal), 4(5), pp. 339-346.

Purwandari, R., Ardiana, A. and Wantiyah. 2013. Hubungan antara Perilaku Mencuci Tangan dengan Insiden Diare pada Anak Usia Sekolah di Kabupaten Jember. Keperawatan Universitas Jember. 4(2). pp. 122-130.

Rompas, M., Tuda, J. and Ponidjan, T. 2013. Hubungan Antara Perilaku Cuci Tangan Pakai Sabun Dengan Terjadinya Diare Pada Anak Usia Sekolah Di Sd Gmim Dua Kecamatan Tareran', Jurnal Keperawatan UNSRAT, 1(1), p. 112846. 
UNICEF. 2020. Infographic: Get the facts on handwashing, Web Page UNICEF. Available at: https://www.unicef.org/stories/infographic-get-facts-handwashing (Accessed: 20 April 2020).

Utomo, A. M., Alfiyanti, D. and Nurahman. 2013. Hubungan Perilaku Cuci Tangan Pakai Sabun (CTPS) Dengan Kejadian Diare Anak Usia Sekolah Di Sdn 02 Pelemsengir Kecamatan Todanan Kabupaten Blora. Jurnal Keperawatan, 6(1), pp. 1-10. doi: 10.1007/s11340-009-9279-9.

Zhang, C. et al. 2013. Promoting clean hands among children in Uganda: a school-based intervention using "typpy-taps". Public Health. 127(6), pp. 586-589. doi: doi:10.1016/j.puhe.2012.10.020. 